\title{
Treatment of acute stroke: a misconception
}

\author{
Rüdiger von Kummer
}

Received: 10 August 2009 / Accepted: 10 August 2009 /Published online: 29 August 2009

(C) Springer-Verlag 2009

\begin{abstract}
"Stroke" is a translation from the Greek term "apoplexy" that first appeared in the writings of Hippocrates (460 to 370 BC) meaning "struck down with violence". It took about 2,000 years until first concepts appeared about the causes of stroke. Johann Jakob Wepfer, a Swiss physician, was the first who differentiated between ischemic and hemorrhagic strokes and described a case of carotid artery disease in 1658, a few years before Thomas Willis, in 1664, published a description of the cerebral vascular anatomy [1]. It is evident now that "stroke" is a quite common clinical syndrome associated with a variety of conditions and diseases. We observe a rapid loss of brain function mainly after the disturbance of cerebral blood supply but as well after all types of intracranial hemorrhages - cerebral, subarachnoidal, sub- and epidural-, in migraine, in encephalitis, in intracranial tumors, after epileptic seizures and hypoglycemia - and we know that all these conditions have a variety of etiologies. In some of these diseases, other factors than impaired blood circulation cause rapid brain dysfunction. Nevertheless, "stroke" became the diagnosis for disturbances of blood supply to the brain due to ischemia or hemorrhage into brain tissue or subarachnoid space and became, thus, more than just a syndrome by implementing a specific pathogenesis caused by a wide variety of diseases. It is evident, however, that "disturbances of blood supply" in brain ischemia and hemorrhage do not represent a useful concept in order to develop effective
\end{abstract}

\footnotetext{
R. von Kummer $(\square)$

Department of Neuroradiology, Dresden University Stroke Center, Universitätsklinikum Carl Gustav Carus,

Fetscherstr. 74,

01307 Dresden, Germany

e-mail: Ruediger.vonKummer@uniklinikum-dresden.de
}

treatment, like the diagnosis of "acute dyspnea" does not give directions for specific and effective treatment.

We can learn from medical history that effective treatment requires the visualization and subsequent understanding of pathology and pathogenesis. In the living human, E. Moniz visualized the cerebral vessels about 50 years before images of the brain itself were obtained with computed tomography (CT) and magnetic resonance imaging [2]. The carotid artery is the section of the cerebral circulation that is best accessible for palpation, auscultation, and treatment. It is, therefore, of no surprise, that first concepts of "stroke" treatment and prevention were based on insights into carotid artery pathology and its consequences for the brain [3-5]. For the first time in the seventies of the last century, CT visualized the brain and enabled the differentiation between "ischemic stroke" and "hemorrhagic stroke" in patients. Since then, a couple of randomized trials studied the effect of tissue plasminogen activator (TPA) in patients with the CT confirmed diagnosis of "ischemic stroke" [6-10]. One of the first trials showed that I.V. infusion of TPA within $3 \mathrm{~h}$ of the onset of ischemic stroke reduces the proportion of patients with disability and death by $7.4 \%$ [6]. The pivotal part 2 of this trial studied whether treatment with TPA resulted in sustained clinical benefit at 3 months after the CT-based diagnosis of ischemic stroke. Among 165 placebo-treated patients, 26 patients $(15.8 \%, 95 \%$ confidence interval (CI) $11 \%$ to $22 \%)$ had an excellent clinical outcome with a modified Rankin score (mRS) of 0 and 1. After TPA treatment, 39 out of 168 patients $(23.2 \%, 95 \%$ CI $17 \%$ to $30 \%)$ had an excellent clinical outcome $(p=0.019)$ [6]. Despite this small treatment effect - no beneficial effect in $92.6 \%$ of the patients treated-I.V. infusions with TPA became the treatment of choice for all patients with "ischemic stroke" for the first 
$3 \mathrm{~h}$ after symptom onset. Moreover, treatment with TPA after $3 \mathrm{~h}$-although not tested - was regarded as risky and strictly contra-indicated. In ECASS 3 , the other positive trial with TPA, patients were treated between 3 and $4.5 \mathrm{~h}$ after stroke onset. In the placebo group, 182 out of 403 patients $(45.2 \%, 95 \%$ CI $40 \%$ to $50 \%)$ had a favorable clinical outcome (mRS: $0-1$ ) at 3 months after stroke, and 219 out of 418 TPA-treated patients $(52.4 \%, 48 \%$ to $57 \%$; intent-to-treat analysis). This means that $7.2 \%$ of patients had a benefit from the treatment, but $92.8 \%$ of the patients had no benefit. Both positive trials showed a relative small effect with a number needed to treat of 14 with early or late treatment. If TPA is given based on the diagnosis of "ischemic stroke", 13 out of 14 "ischemic stroke" patients have no benefit. Nevertheless, this treatment is now widely regarded as standard of care.

A combined analysis of all major randomized TPA trials in acute ischemic stroke revealed a decrease in the proportion of patients with favorable clinical outcomes (mRS:0-1) with increasing time to treatment from $41 \%$ within the first $90 \mathrm{~min} 37 \%$ in patients being treated between 271 to 360 minutes after stroke [11]. During this time period, the proportion of patients with spontaneous favorable clinical outcome increased from $29 \%$ to $36 \%$ resulting in a decline of "TPA response" with increasing time from stroke onset to treatment (Fig. 1.) The impression of a decline in TPA response with the delay of treatment initiation in "ischemic stroke" stimulated the hypothesis that infarct growth is the cause for the failure of treatment. It is not considered so far that a selection-bias with less diseased patients in later time groups is mainly responsible for the smaller response to TPA.

As stated recently, we are confronted with the problem, that all these randomized trials included patients just with the diagnosis of "ischemic stroke" and did not care whether these patients had an arterial occlusion with a thrombus that could be solved with TPA [12]. The type and site of arterial

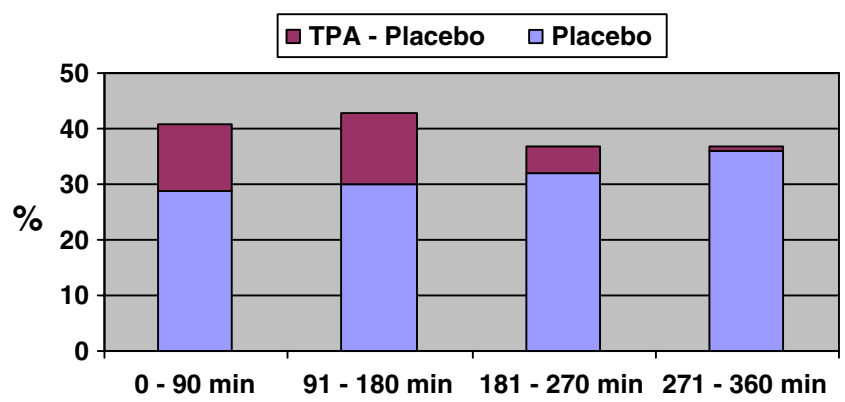

Fig. 1 Proportion (\%) of patients with favorable clinical outcome (mRS, 0-1) after ischemic stroke after treatment with TPA (whole columns) and placebo (blue columns) at different time periods (min) after stroke onset according to [11] obstruction was not assessed, neither the underlying vessel disease. Moreover, there was no check whether the treatment resulted in recanalization and reperfusion. In consequence, we have no idea why TPA works in one patient, but not in the other. For everybody, who has used TPA intra-arterially, there is no doubt that TPA can recanalize arteries. We should, therefore, not blame the drug for ineffectiveness, but our approach to identify patients who will benefit from this special treatment.

As already mentioned [12], ischemic stroke patients do not benefit from thrombolytics because of three main reasons:

1. Thrombolysis is not required because of spontaneous recanalization with subsequent recovery.

2. The treatment with I.V. rt-PA does not recanalize the obstructed artery, or recanalization does not result in reperfusion.

3. Recanalization and reperfusion of ischemic brain tissue is achieved, but too late to enable the recovery of brain functions.

It can be presumed that spontaneous restoration of cerebral blood flow is the main reason for spontaneous clinical recovery. We should study then whether patients without arterial obstruction on CTA or MRA have any benefit from I.V. thrombolytics. It can further be presumed that failure of recanalization or prompt re-occlusion is a main reason for the failure of I.V. thrombolytics. The CLOTBUST-investigators observed that persistent occlusion and reocclusion are the main reasons for clinical deterioration after TPA treatment [13]. The same group confirmed earlier observations that an occlusion of the distal internal carotid artery can hardly recanalized with I.V. TPA $[14,15]$. Another group showed that the effect of I.V. TPA is minimal in arterial tandem obstructions [16]. From these observations, it is clear that patients should be differentiated based on angiographic findings and monitored during and after TPA infusion in order to identify those who do not recanalize.

It is possible that patients do not recover and even deteriorate clinically despite successful arterial recanalization [17]. It is a matter of debate which image modality and which image information can best predict a favorable response to reperfusion therapy [18]. There is wide agreement, however, that an effective treatment and secondary prophylaxis after stroke requires detailed information about cerebral vessels and tissue.

I have the strong suspicion that the ancient diagnosis "stroke" is influencing the thinking of stroke physicians and hinder from exact diagnosis. We should abandon this term and replace it by individual diagnosis with description of pathology for all patients who had suffered from a stroke syndrome. 
Conflict of interest statement R. von Kummer is and has been a member of committees in various trials of acute stroke treatment (ECASS, ECASS 2, ECASS 3, DIAS, DEDAS, DIAS-2, DIAS-3). He has received honoraria for service from Boehringer Ingleheim, Paion, Forest Lab, and Lundbeck.

\section{References}

1. Thompson J (1996) The evolution of surgery for the treatment and prevention of stroke. The willis lecture. Stroke 27:1427-1434

2. Moniz E (1927) L'encephalographie arterielle: son importance dans la localization des tumeurs cerebrales. Rev Neurol (Paris) 2:72-90

3. Moniz E, Lima A, de Lacerda R (1937) Hemiplegies par thrombose de la carotide interne. Presse Med 45:977-980

4. Fisher C (1951) Occlusion of the internal carotid artery. Arch Neurol Psychiatry 65:346-377

5. Fisher C, Adams R (1951) Observations on brain embolism with special reference to the mechanism of hemorrhagic infarction. $\mathrm{J}$ Neuropathol Exp Neurol 10:92-94

6. The National Institute of Neurological Disorders and Stroke rt-PAStroke Study Group (1995) Tissue plasminogen activator for acute ischemic stroke. N Engl J Med 333:1581-1587

7. Clark W, Wissman S, Albers G, Jhamandas J, Madden K, Hamilton S (1999) Recombinant tissue-type plasminogen activator (alteplase) for ischemic stroke 3 to 5 hours after symptom onset. The atlantis study: a randomized controlled trial. Alteplase thrombolysis for acute noninterventional therapy in ischemic stroke. JAMA 282:2019-2026

8. Hacke W, Kaste M, Bluhmiki E, Brozman M, Davalos A, Guidetti D, Larrue V, Lees K, Medeghri Z, Machnig T, Schneider D, von Kummer R, Wahlgren N, Toni D (2008) Thrombolysis with alteplase 3 to 4.5 hours after acute ischemic stroke. N Engl J Med 359:1317-1329

9. Hacke W, Kaste M, Fieschi C, Toni D, Lesaffre E, von Kummer R, Boysen G, Bluhmki E, Höxter G, Mahagne M, Hennerici M (1995) Intravenous thrombolysis with recombinant tissue plasminogen activator for acute hemispheric stroke. The European
Cooperative Acute Stroke Study (ECASS). JAMA 274:10171025

10. Hacke W, Kaste M, Fieschi C, von Kummer R, Davalos A, Meier D, Larrue V, Bluhmki E, Davis S, Donnan G, Schneider D, DiezTejedor E, Trouillas P (1998) Randomised double-blind placebocontrolled trial of thrombolytic therapy with intravenous alteplase in acute ischaemic stroke (ECASS II). Lancet 352:1245-1251

11. The ATLANTIS, ECASS, and NINDS rt-PA Study Group Investigators (2004) Association of outcome with early stroke treatment: pooled analysis of ATLANTIS, ECASS, and NINDS rt-pa stroke trials. Lancet 363:768-774

12. von Kummer R (2009) Why is the treatment with intravenous rtpa ineffective in the majority of acute ischemic stroke patients? Clin Neuroradiol 19:3-5

13. Saqqur M, Molina CA, Salam A, Siddiqui M, Ribo M, Uchino K, Calleja S, Garami Z, Khan K, Akhtar N, O'Rourke F, Shuaib A, Demchuk AM, Alexandrov AV (2007) Clinical deterioration after intravenous recombinant tissue plasminogen activator treatment: a multicenter transcranial doppler study. Stroke 38:69-74

14. Jansen O, von Kummer R, Forsting M, Hacke W, Sartor K (1995) Thrombolytic therapy in acute occlusion of the intracranial internal carotid artery bifurcation. AJNR Am J Neuroradiol 16:1977-1986

15. Saqqur M, Uchino K, Demchuk AM, Molina CA, Garami Z, Calleja S, Akhtar N, Orouk FO, Salam A, Shuaib A, Alexandrov AV (2007) Site of arterial occlusion identified by transcranial doppler predicts the response to intravenous thrombolysis for stroke. Stroke 38:948-954

16. Rubiera M, Ribo M, Delgado-Mederos R, Santamarina E, Degado P, Montaner J, Alvarez-Sabin J, Molina C (2006) Tandem internal carotid artery/middle cerebral artery occlusion. An independent predictor of poor outcome after systemic thrombolysis. Stroke 37:2301-2305

17. von Kummer R, Allen K, Holle R, Bozzao L, Bastianello S, Manelfe C, Bluhmki E, Ringleb P, Meier D, Hacke W (1997) Acute stroke: usefulness of early CT findings before thrombolytic therapy. Radiology 205:327-333

18. von Kummer R (2009) Changing directions in acute stroke diagnostics. Good-bye "Mismatch"? Clin Neuroradiol 19:105-107 